\title{
Investigation and Analysis on Graduation Thesis Topic Selection Trend of Japanese Major
}

\author{
Yu Cong \\ Dalian Neusoft University of Information, Dalian, Liaoning, China
}

Keywords: Japanese major; thesis topic; topic selection trend

\begin{abstract}
Based on the theory of OBE education and teaching reform, graduation thesis topic selection of Japanese major in colleges and universities should also be innovated centered by students' study results. Topic selection is the primary link for graduation project. The graduation thesis topic selection characteristics, sources, types, changes and development trends in recent years are analyzed through sorting out and analyzing the graduation thesis topic selection situation of graduates who are majored in Japanese in Dalian Neusoft University of Information from 2013 to 2017, aiming at providing references for college and university teachers to guide the graduation thesis.
\end{abstract}

\section{Introduction}

Syllabus of Senior Study Stage of Japanese Major in Colleges and Universities indicated that students should master the solid Japanese basic knowledge and comprehensive practical ability when they graduate, and should also learn about the knowledge related to Japanese literature, culture, economy and linguistics, etc. As an important link of implementing undergraduate education training target, graduate project (thesis) is one of the significant approaches for testing students' all-round practical ability. In the new "national standard", it indicated the diversification need of graduation thesis that graduation thesis (project) aims at cultivating and testing students' ability of comprehensively applying the learned theoretical knowledge, problem-solving ability as well as innovative ability. Graduation thesis topic selection should conform to professional cultivation goals and specifications. As required by syllabus and the new "national standard, graduation thesis topic selection should be developed multifariously. Multiple forms such as academic papers, translation works, practice reports and investigation reports can be adopted. The thesis can be written in either Chinese or Japanese. At present, what are the characteristics, direction changes and development for graduation thesis topic selection of students majored in Japanese, and how to guarantee the topic selection quality become the issues which need to be considered and explored in this paper. In order to learn about the current status, characteristics and development trend of graduation thesis topic selection of Japanese major, the author collected and sorted out the related information of graduation thesis topic selection of the students majored in Japanese from 2013 to 2017, analyzing characteristics direction changes and development trends of topic selection of student majored in Japanese from direction, source and types of graduation project topic selection, which aims at better and more comprehensively providing reference data and information of advisers of graduation thesis of Japanese major.

\section{Previous Researches}

The author collected eight relevant papers written between 2002 and 2017 in virtue of CNKI based on "undergraduate thesis topic selection of Japanese major". Analyzing from publishing year and trend table, 2010, 2011, 2014 as well as 2017 are the research peak. The author selected the most representative papers to analyze and discuss the previous researches of undergraduate thesis topic selection of Japanese major.

Liu Wenqi (2014) proposed in Several Opinions in Improving Undergraduate Thesis of Business Japanese Major that the problems existed in graduation thesis include lacking of readability, 
improper topic selection, and low writing level, etc. Correspondingly, the countermeasures for solving problems and improving graduation thesis quality are proposed.

Wan Hongmei (2015) indicated the prominent problems and factors influencing topic selection in the Strategies and Construction of Undergraduate Thesis Topic Selection of Japanese Major. The prominent problems include incorrect subjects, and improper topic selection width and depth, while there are lots of factors, such as unreasonable curriculum setup and topic selection time, lacking of research document, and lacking of experience. Based on analyzing its factors, the countermeasures such as adjusting curriculum setup and topic selection time and implementing academic tutorial system are proposed.

Li Xiaoyu (2017) indicated the problems for undergraduate thesis topic selection of Japanese major in Exploration on Undergraduate Thesis Topic Selection of Japanese Major, including blind, optional, outmoded, and identical topic selection, inconformity with the standard, etc. thus, the principles and methods for topic selection are analyzed.

In conclusion, there are the following problems for the undergraduate thesis topic selection of Japanese major at present: 1. Improper topic selection; 2. Limited writing ability; 3. Lacking of experience; 4. Outmoded topic selection and lacking of innovation. Aiming at the problems, the correspondingly solutions are proposed and moreover, the factors influencing topic selection are also analyzed.

The author found that in the previous researches, it lacks of the analysis on characteristics, changes and development trends of undergraduate thesis topic selection of Japanese major. On this basis, starting from the topic selection results of the recent five years, the topic selection direction, types and sources are learned first. Then, topic selection characteristics, changes and development trends are analyzed. Last, the suggestions and countermeasures for supervising and guaranteeing the topic selection quality are proposed.

\section{Investigation Objects and Methods}

\subsection{Investigation objects}

In this paper, a total of five graduation thesis topic selection summary sheets [1-5])from the previous students (2013-2017) majored in Japanese is selected, sorting out a total of 1256 titles, 251 titles from grade 2013, 242 from 2014, 275 from 2015, 248 from 2016, and 239 from 2017. Because all the graduation theses chosen are qualified, all data are valid.

Investigation projects include topic selection direction, types and sources. Investigation starts from screening the topic selection direction, types and sources of graduates in every grade, followed by sorting out and calculating the data with EXCEL, making the table 1and figure 1 Direction proportion of graduation thesis topic selection of Japanese major in five grades from 2013 to 2017 with the data, and diagrammatizing the data of topic selection direction. In the end, the graph data are analyzed respectively.

\subsection{Investigation methods}

The common data EXCEL statistics and chart data analysis methods are adopted. The broken line graph is adopted for trend analysis. In topic selection direction analysis, the statistics is conducted according to the categories including business economy, social culture, linguistics and education, literature and information technology. The statistics data is diagrammatized as a broken line graph for the subsequent analysis and discussion.

\section{Investigation results and analysis}

Investigation results show that undergraduate thesis topic selection direction of Japanese major presents the following characteristics: first, business economy occupies a great proportion (44\%) as for the amounts, which basically conforms to the cultivation need of business application talents of Japanese major of the school; second, social culture ranks the second (36\%), lots of graduates choose social culture because of lots of documents, easy and fast for literature research, plenty 
research methods, and multiple achievements for references; third, linguistics and education occupy $14 \%$, students who choose this direction are students who are attending postgraduate entrance exams and abroad students, with strong specialty and difficulties, so only few students choose this direction. The literature only accounts for $1 \%$, and it can be seen that students' interest in Japanese literature is low. And meanwhile, it is difficult to write, the teacher resource in literature direction is insufficient. The information technology accounts for $4 \%$, for students majoring in linguistics, information technology is renegade from their major, so there are very few students choose this direction naturally.

Table 1 Direction proportion of graduation thesis topic selection of Japanese major in five grades from 2013 to 2017 [1-5]

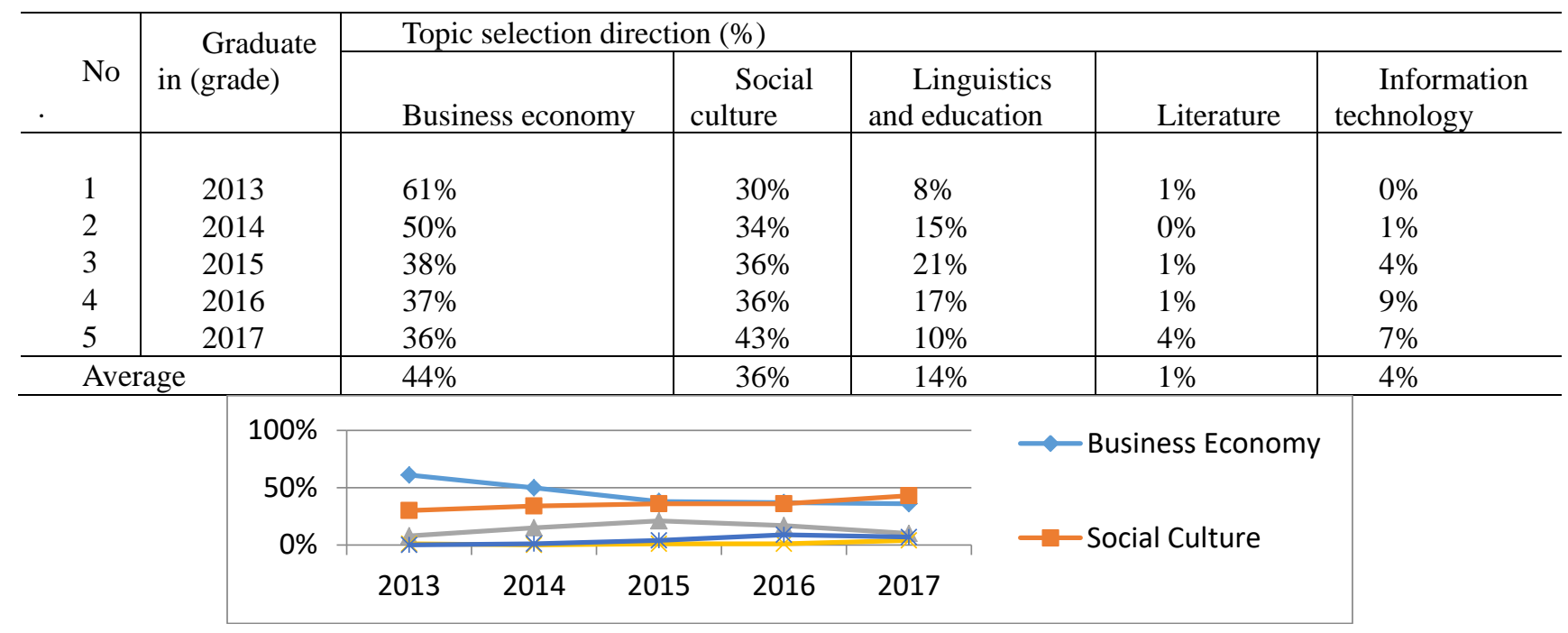

Fig 1 Direction proportion of graduation thesis topic selection of Japanese major in five grades from 2013 to 2017 [1-5]

Investigation results show that business economy direction presents the decreasing trend year by year; social culture presents increasing trend year by year; linguistics and education reached the peak by the grade 2015 and later present the decreasing trend, and for other grades, the changes are small. Literature and information technology develop steadily. Overall, the topic selection of business economy changes a lot, even though it presents decreasing trend, it is also ranked top one. Social culture changes small, presents steady rising trend, and was improved obviously in 2017. From the data, $80 \%$ graduates' topic selection is centralized in these two directions. Linguistics and education, literature, and information technology occupy a total of $20 \%$.

Based on investigating direction proportion and trend of graduation thesis topic selection in five grades, the topic selection types are analyzed. According to the relevant explanation of the school about graduation thesis, the topic type of graduation thesis topic selection is divided into the following categories:

Table 2-Topic type symbol and category table[1-5]

\begin{tabular}{|c|c|}
\hline Symbol & Type \\
\hline AX & Project design true topic \\
\hline AY & Engineering design simulation project \\
\hline $\mathrm{BX}$ & Technical development true topic \\
\hline CX & Software engineering true project \\
\hline CY & Software engineering simulation project \\
\hline $\mathrm{DX}$ & $w_{9}$ Theoretical research true project \\
\hline DY & Theoretical research simulation project \\
\hline EX & $\xi_{9}$ Applied research true project \\
\hline EY & $\xi_{9}$ Applied research simulation project \\
\hline FX & Practice report true project \\
\hline FU & Practice report simulation project \\
\hline
\end{tabular}


Among which, the mark “毁” suits for topic selection scope of Japanese major. Graduates can choose according to the topic selection types.

DX- Theoretical research true project: 1, Graduation thesis is the empirical study conducted based on an actual phenomenon or practice, or the project which can achieve the world's research results. 2, Students participate in vertical project topic and write graduation thesis based on vertical project contents.

DY- Theoretical research simulation project: the thesis written based on a kind of theoretical theories.

EX-Applied research true project: 1 . Students write graduation thesis according to the specific internship practice and innovative and entrepreneurship experience (including innovative and entrepreneurship programs). 2. Students conducted the related researches and write graduation thesis based on engineering practice experience and combining with the related theories (students participate in teachers' horizontal projects, etc.).

EY- Applied research simulation project: students conduct the researches through social investigation activities. The main investigation forms include questionnaire investigation, interview, and first-hand information collection, etc.

Table 3 Undergraduate Thesis Topic Source and Type Proportion Distribution List of Japanese Major from 2013 to 2017 [1-5]

Undergraduate Thesis Topic Source and Type Proportion Distribution List of Japanese Major from 2013 to 2017

\begin{tabular}{|c|c|c|c|c|c|c|c|c|}
\hline \multirow[b]{2}{*}{ Year } & \multirow[b]{2}{*}{$\begin{array}{l}\text { Number } \\
\text { of } \\
\text { students }\end{array}$} & \multicolumn{3}{|c|}{ Proportion of source (\%) } & \multicolumn{4}{|c|}{ Proportion of types } \\
\hline & & $\begin{array}{l}\text { School } \\
\text { teaching }\end{array}$ & $\begin{array}{l}\text { Internship } \\
\text { and } \\
\text { practice }\end{array}$ & $\begin{array}{l}\text { Teacher research } \\
\text { projects } \\
\text { (horizontal-vertical) }\end{array}$ & $\mathrm{DX}$ & DY & EX & EY \\
\hline 2013 & 251 & $90 \%$ & $8 \%$ & $2 \%$ & $8 \%$ & $29 \%$ & $14 \%$ & $49 \%$ \\
\hline 2014 & 242 & $100 \%$ & $0 \%$ & $0 \%$ & $31 \%$ & $18 \%$ & $13 \%$ & $38 \%$ \\
\hline 2015 & 275 & $92 \%$ & $0 \%$ & $8 \%$ & $8 \%$ & $28 \%$ & $13 \%$ & $51 \%$ \\
\hline 2016 & 242 & $80 \%$ & $7 \%$ & $13 \%$ & $35 \%$ & $21 \%$ & $15 \%$ & $29 \%$ \\
\hline 2017 & 239 & $88 \%$ & $11 \%$ & $1 \%$ & $17 \%$ & $10 \%$ & $4 \%$ & $69 \%$ \\
\hline Average & 250 & $90 \%$ & $5 \%$ & $5 \%$ & $20 \%$ & $21 \%$ & $12 \%$ & $47 \%$ \\
\hline
\end{tabular}

From table 3, it can be seen that most of graduation thesis topics are come from school teaching, and the forms of students' self-planning or communicating with their advisers are in the majority. Enterprise internship has been rising from the grade 2016 and reached 11\% in grade; the proportion of teachers' scientific projects fluctuated unsteadily in recent years, and the proportion accounted by grade 2016 is greater than that of other grades.

In addition, EY- applied research simulation projects occupies the highest proportion, which illustrates that students are happy to conduct their research projects through social investigation activities, with the forms such as investigation, interview, questionnaire, and first-hand information. DY- theoretical research simulation project and DX applied research true project occupy $21 \%$ and $20 \%$ respectively, which explains that the students' proportions for studying based on theoretical research true project and research simulation project are almost the same. EX applied research true project accounts for $12 \%$, which can be seen that only few students write graduation thesis based on enterprise internship and innovative and entrepreneurship experience (including innovative and entrepreneurship programs). Moreover, also very few students write graduation thesis based on engineering practice experience and combining with the related theories. Advisers should further conduct the related work.

\section{Suggestions on Graduation Thesis Topic Selection Direction}

Correctly guiding the thesis topic selection is the direct factor influencing the quality of graduation thesis. Combining with the graduation thesis topic selection situation of 5 grades, few suggestions are proposed on high-quality thesis topic selection. 


\subsection{Advisers are suggested to closely combine the standards and demands of Japanese major starting from topic selection types}

Students should consider from the contents of Japanese major: literature, linguistics, teaching methods, translation, culture, business, and all kinds of investigation reports combining with the practice.

Table 4 Topic selection categories and research sampling

\begin{tabular}{|l|l|}
\hline Literature & $\begin{array}{l}\text { Researches related to building the authors' personality, related to the authors' destiny, } \\
\text { language styles, evaluation, the works' evaluation, the authors' and works' evaluation, } \\
\text { researches related to the authors and works, the authors' psychology, and the problems } \\
\text { reflects by the authors, etc. }\end{array}$ \\
\hline Linguistics & $\begin{array}{l}\text { Linguistic structure (vocabulary; semantic; grammar; discourse); linguistic application } \\
\text { (rhetoric, style, variation.); linguistic theory (phonology, semantics, grammar, pragmatics. } \\
\text { psycholinguistics, and sociolinguistics.) }\end{array}$ \\
\hline $\begin{array}{l}\text { Teaching } \\
\text { methods }\end{array}$ & $\begin{array}{l}\text { Japanese study problems; Japanese teaching problems (teaching objects, methods, means, } \\
\text { techniques, environment, textbooks, evaluation and teachers' quality, etc.); Japanese study } \\
\text { case research; Japanese teaching case research; learners' self-management; Japanese study } \\
\text { strategies. }\end{array}$ \\
\hline Translation & $\begin{array}{l}\text { Japanese-Chinese translation methods and skills; translation works' case study; } \\
\text { comparative study on translated copies; translation theories, translators and authors, } \\
\text { translators and readers. }\end{array}$ \\
\hline Culture & $\begin{array}{l}\text { Traditional and modern Japanese value and belief; Japanese religion; Japanese education; } \\
\text { Japanese society; Japanese family; last name, appellation, greeting, introduction, } \\
\text { compliment, banquet custom, meeting, visiting, gift giving etiquette, privacy, and taboo, } \\
\text { etc. }\end{array}$ \\
\hline Business & $\begin{array}{l}\text { Corporate management; business negotiation; international economy; international trade; } \\
\text { e-commerce }\end{array}$ \\
\hline $\begin{array}{l}\text { Pll kinds of investigation reports combining with practice; corporate internship reports } \\
\text { related to the major, etc. }\end{array}$ \\
\hline
\end{tabular}

\subsection{It is suggested to categorize combining with the school's graduation thesis topic selection standards as for topic selection requirements.}

Such as economic trade, Japanese society and culture, Japanese literature, Japanese education, and Japanese linguistics. Moreover, the connotations of each study direction are indicated, allowing more students to understand the basic connotation of the study directions.

Economic trade: Making students understand that the thesis topic selection of Japanese economy should surround the topics such as Japanese economy, trade, finance, e-commerce, investment, operation philosophy and strategy, and localization of Japanese enterprises in China.

Example 1: Causal Study on Japanese Economic Hotspot Phenomenon

Example 2: Analysis on Japanese Corporate Cultural Characteristics

Example 3: Study and Discussion on the Japanese Corporate Strategies with Referential Significance

Example 4: Discovery and Study on Localization of Japanese Enterprises in China

Example 5: New Trends of Japanese Economy under the Informatization and Globalization Era Backgrounds

Japanese society and culture: first, making students understand the general culture refers to the sum of physical wealth and spiritual wealth created in human's historical practice process, while narrow culture refers to social ideology and the corresponding system and organizations. Sometimes, it also refers to the spiritual wealth in the aspects such as education, science, literature and arts, thus to be distinguished from the knowledge and facilities in the aspects such as economy, 
politics, and military. Students can consider the topic selection from the following aspects: comparison on Chinese and Japanese culture; cultural linguistics; Japanese culture; social culture.

Example 1: Comparative Study on Design and Application of Accessible Public Facilities in China and Japan

Example 2: A Brief Analysis on Enlightenment of Exporting “Japanese Strategies” to Chinese Culture

Example 3: Discussion on the Similarities and Differences of Sino-Japanese Craftsman Spirit in Post-industrial Era

Example 4: Analysis on Tolerance and Characteristics of Japanese Foreign Culture

Example 5: Analysis on the Role of Emotion Text in the Communication of Japanese Young People

Japanese literature: in Japanese literature field, there are lots to topics without the fixed research directions and modes. However, combining with its research contents and methods, we can divided the undergraduate thesis of Japanese literature research into the following categories: literature work researches, researches on literary schools and literary trends, literary genre researches, as well as comparative literature researches. However, for undergraduate thesis, it is very difficult for students to innovate when the reading volume and time are limited. Considering the thesis publishing situation in recent years, the research hotspots are listed as follows: literature work researches, researches on literary schools and literary trends, literary genre researches, as well as comparative literature researches.

Example 1: Research and Discussion on Authors' Ideas Centralized by a Work

Example 2: Comparative Research on Different Works of the Same Author

Example 3: Discussion on the Author's Literature Accomplishment from a Literature Work

Example 4: Analysis on Personal Character in Literature Works

Example 5: The Relationship between Characters in Literature Works

Japanese education: topic selection in Japanese teaching is extensive, including teaching theories and applications, listening, speaking, reading, writing, translating and other linguistic skills, teaching of phonetics, grammar, vocabulary and other phonetic knowledge, teaching of sociocultural knowledge related to verbal communication, Japanese study methods and strategies, course design, textbooks' analysis, writing, test, evaluation and others. Japanese teaching researches suitable for undergraduates' professional thesis are divided into two categories: researches centered by teaching activities, and researches centered by students' study.

Example 1: Study on Teaching Effects' Evaluation

Example 2: Penetration and Integration of Japanese Enterprises' Culture in Teaching

Example 3: Investigation and Research on Practice and Application of Teaching Methods

Example 4: Study on a Station Learning Bias

Example 5: Study on Pragmatics of Students Majoring in Japanese

Japanese linguistics:

Japanese linguistics research belongs to linguistics scope. Japanese language has its own characteristics, such as complex honorific, influenced by Chinese, English and other western languages. When writing graduation thesis, students should fully absorb domestic and overseas research results, choose the topics related to linguistics, including vocabulary, grammar, rhetoric and others. The specific scope includes semantics, syntax, pragmatics, discourse analysis, sociolinguistics, language and culture, etc. Such as Japanese vocabulary study; Japanese syntactic study.

Example 1: Comparative Study of Chinese and Japanese Homographs

Example 2: Comparative Study of Chinese and Japanese Homonyms

Example 3: Researches on Japanese Expression

Example 4: Study of Words Centered on Certain Kinds of Words

Example 5: Comparative Study of Chinese and Japanese Vocabulary Centered by Certain Kinds of Words 


\section{Conclusion}

Based on the relevant investigation on graduation thesis topic selection of Japanese major in the school, it is summarized that students give priority to business economy when selecting topics, which conforms to the cultivation needs to business application talents of Japanese major. However, it presents the decreasing trend year by year from the chart, while social culture presents the increasing trend, and there are lots of causes, for example, the number of students who are going to attend the postgraduate entrance exams increases a lot, and limited by the major, they can only choose the majors related to language. The literature occupies the smallest proportion, which explains that students' study enthusiasm on the topics related to the literature is low, and coupled with lacking of teachers and difficult in writing, very few students choose this direction. From the topic source, it mostly comes from the school teaching, and the forms of students' self-planning or communicating with their advisers are in the majority. From the grade 2016, serving as interns in enterprises has presented the rising trend. In addition, from the investigation data, it can be seen that the topic selection types also become diversified. EY-applied research simulation project occupies a higher proportion than others, which illustrates that students are happy to conduct their research topics through social investigation activities, and the first-hand documents are easy to be achieved through the forms such as questionnaire investigation and interview. The proportions occupied by both DY- theoretical research simulation project and DX applied research true project are very nearly the same, which illustrates that there are students try to study the theoretical or true projects. EX applied research true project occupies a small proportion, and few students conduct the related researches based on engineering practice and combining with the related theories, which illustrates that how interns transfer the practice results into paper achievements needs to be further guided.

Based on the above investigation results, the author summarized the following suggestions for graduation thesis topic selection of Japanese major:

Guiding students:

Referring to literatures, based on the previous researches, students should be brave to think and innovate, propose their unique ideas.

After the topic is determined, students should collect documents extensively surrounding the topic, and guarantee to possess the related linguistic theoretical knowledge and master the related scientific research methods.

During the proposition and analysis, students should introduce the background clearly, define the related concepts accurately, and try to make their theses more persuasive.

The language should be concise and accurate.

The logic thinking should be employed fully, proving the viewpoints from multiple perspectives including comparison, analogy and disproof.

The deduction should be used more, making a point first and supporting the point with argument.

In the argument, it is better to employ data, charts, statistics, and investigation analysis, etc.

Teachers' guidance:

The guidance should conform to the basic requirements of syllabus, showing and highlighting the major's characteristics and features.

When guiding students, teachers should ask students to choose the innovative and meaningful topic, and it depends on the paper contents, instead of the title.

Guiding students to find out their interests, and conduct the preparation starting from the reality.

Highlight that the topic selection scope should be controlled, and the topics should be focusing and clear.

Reminding students that the document collection is crucial, and asking them to select the topic with abundant documents.

Guiding students to avoid the very professional or advanced topics.

Guiding students to lay emphasis on topic selection steps and methods: topic selection direction (interests, and accumulation of knowledge), exploration, and document viewing. Narrow the range of topic selection.

Notes: 
[1] Graduation Thesis Topic Selection Summary Sheet between 2012 and 2013 (Japanese major) 2013.3

[2] Graduation Thesis Topic Selection Summary Sheet between 2014 and 2015 (Japanese major) 2014.3

[3] Graduation Thesis Topic Selection Summary Sheet between 2015 and 2016 (Japanese major) 2015.3

[4] Graduation Thesis Topic Selection Summary Sheet between 2016 and 2017 (Japanese major) 2016.3

[5] Graduation Thesis Topic Selection Summary Sheet between 2017 and 2018 (Japanese major) 2017.12

[6] Relevant Explanation about Graduation Thesis Topic Selection of Japanese Major in Dalian Neusoft University of Information (Japanese major) 2017.11

\section{References}

[1] Liu Wenqi, Several Opinions in Improving Undergraduate Thesis of Business Japanese Major [J] Higher Education 2014(1) 116-119.

[2] Wan Hongmei, Strategies and Construction of Undergraduate Thesis Topic Selection of Japanese Major [J] Journal of Changshu Institute of Technology (Science of Education) 2015(11)51-63.

[3] Li Xiaoyu, Exploration on Undergraduate Thesis Topic Selection of Japanese Major [J] Journal of Xiangyang Vocational and Technical College 2017(7) 22-26.

[4] Xiang Hang, New Connotation of Undergraduate Thesis in Practical Teaching of Foreign Language [J] Heilongjiang Education (High Education Research and Evaluation) 2013(11)12-19.

[5] Syllabus of Senior Study Stage of Japanese Major in Colleges and Universities [M] Japanese Group of Foreign Language Professional Teaching Steering Committee of Colleges and Universities of Ministry of Education, Dalian University of Technology Press, 2000. 